\title{
PROMPT PHYSICAL AVAILABILITY OF THE MILITARY - CONCEPTS, PRINCIPLES, COMPONENTS
}

\author{
Lt.Col.Sup.Instr. George-Florin BĂIŢAN, PhD*
}

\begin{abstract}
Endurance (the ability to sustain activity), strength (the ability to overcome endurance) and motor skills (the functional application of force and endurance to react operatively to stimuli in the form of effective movement) are essential features for the physical performance of the military and, on a larger scale, for their success in the military system. Prompt physical availability is the ability to meet the physical requirements of any service or combat situation, in order to fulfill the mission or continue the fight until victory is achieved. Looking ahead, the multi-field approach in military operations identified the need for the military to be constantly physically prepared so that they would be available to fight in extreme environments of dispute and difficulty. Both tactical and physical training will remain a key component of combat training, and military physical education specialists must find solutions to integrate physical training into tactical field training exercises.
\end{abstract}

Keywords: prompt physical availability; concepts of training; physical training; workout; military physical education.

The military physical education system creates for the military the daily opportunity to hone their motor skills and abilities necessary for the accomplishment of missions. The specific physical training is rooted in the principles of sports training and its general methodological requirements, designed to build an athletic military, including training activities that directly support the combat tasks of the entire spectrum of operations.

The general objective of the training program of prompt physical availability is to prepare soldiers who are physically able to perform their own tasks or missions, both during physical training and in real combat situations. To achieve this goal, physical activities in the training program must address the following aspects: the development of sufficient strength to perform the necessary tasks and adequate endurance to sustain activity over a long period of time, the development of adequate muscle tone, correcting and maintaining an optimal body weight and improving certain basic motor skills and utility-applications that are essential for the safety of personnel and for effective performance in combat.

Military leaders around the world have always recognized that the effectiveness of the military depends largely on their physical condition. Full-

\footnotetext{
* "Ferdinand I" Military Technical Academy e-mail: baitan_george_florin@yahoo.com
}

spectrum operations (combat, stability and support or peacetime operations) place a special emphasis on the qualities, skills and motor skills of the military, components on which largely depends the final victory or even the lives of combatants. To march long distances with cargo (equipment and combat armament) equipped to travel a varied terrain and fight effectively on arrival in the battlefield, to lift and transport heavy objects, to drive high-speed military vehicles on rugged terrain, to storm enemy positions by sprinting and crawling long distances, to jump or climb certain obstacles, to dig trails, to fill sandbags or to remove residual materials, and to make a quick move several hours without a break all these acts of war and many more require prompt physical availability from the military.

\section{General aspects of prompt physical availability to the military}

"Physical training aims to satisfy the physical requirements of the armed struggle from the perspective of the military for the performance of duties or missions received". The physical training of the military has evolved over time based on interdisciplinary scientific approaches (military and civilian) in the field of physical education. This historic research as well as contemporary concepts influence the scheduling of physical activities in the army. Physical training programs must be designed to meet the training objectives of the military, the subunit/unit and, by extension, the army. Even if there are similarities with the physical 
training programs in civilian life, in the military system the specifics of the fight and the dangers of the profession require a different approach. This approach can be called prompt physical availability (DFP) and refers to the quality or condition of the military to be permanently physically trained, integrating old training concepts, such as:

- Low intensity training - is a program of cardiovascular exercises in which the military performs aerobic activity at a low to moderate intensity for a long and continuous period of time. Once the intensity is reached, the exercise can continue as long as the soldier can maintain his heart rate in a prescribed training $\operatorname{area}^{2}$ (a level at which the heart is trained, but not exhausted), and his energy continues to be available;

- Tempo training - is a comfortable run, for a longer period of time (20-30 minutes), at a pace set for a certain distance or at a certain level of perceived effort for a certain time ${ }^{3}$. It is simply the level of effort at which the body is able to eliminate an amount of lactic acid (a byproduct of burning carbohydrates) equal to that produced. This means that the sensations of heavy legs or weak arms will no longer be installed. If this type of training is performed intermittently, then it will be similar to interval training;

- High Intensity Interval Training - is based on a fundamental principle: the alternative repetition of a short period of high intensity resistance training with a longer recovery period. It can be performed using traditional exercises that stimulate aerobic effort (running) or relying mainly on intensive use of muscles in various regions of the body (plyometric exercises). In addition to the fact that it contributes to improving the health of the military, interval training creates a superior state of well-being among those who perform it, who want to practice this type of training in the future;

- Circuit training - is a popular and very effective training method over time, an excellent way to improve cardiovascular capacity and muscular endurance. It will raise the heart rate and keep it high throughout the circuit due to short recovery periods, large muscles worked at the same time and a combination of exercise that requires the whole body. Circuit training is an excellent choice for the physical training of the military, especially if the training time is short, if they get bored quickly or if they do not like to train alone, things that make it ideal for group training in a limited space;
- Cross training - is a method of fitness that involves several different types of exercise, which will be rotated in different ways during the program of a week or during a training session. It does not have to be very intense because, in essence, it is about combining workouts that will support each other and require more muscle groups, improving agility and facilitating participation in a variety of recreational sports. Cross-training limits the stress that occurs on certain muscles, as different activities use the muscles in slightly different ways. In addition, Cross Training reduces boredom and keeps the military motivated;

- Push-pull training - generally refers to strength training sessions centred around muscle groups that perform similar actions, alternating between agonist and antagonist muscles. Thus: the "pull" training will train the muscles of the upper back, biceps and forearms, while the "push" training will train the muscles of the chest, triceps and shoulders. This training session should also include a training session for the lower limbs and abdomen, thus creating one of the most effective programs for increasing muscle mass;

- "Upper-lower" training - refers to strength training sessions in which the major muscle groups of the upper body are worked alternately, in separate sessions, then those of the lower part. This will allow you to perform workouts on successive days, as there is no overlap between the required muscles in two consecutive workouts. This type of training offers an opportunity for diversity, because the military is not limited to certain muscle groups for each training, but can choose from a wide range of exercises. Thus, they can perform completely different exercises in each workout, a variety that will help them stay involved and avoid boredom;

- "agonist - antagonist" training (Superset) is a form of strength training in which two opposing muscle groups are worked, moving quickly from one exercise to another, without taking a break for rest between sets (at most one short rest for hydration). Supersets can be used as a way to do more exercise in a limited amount of time, because by not pausing, the muscles that have been required in a series of exercises will recover during the next set in which they are not involved. Supersets focus on endurance (as well as skill), as the lack of physical recovery between sets can be extremely challenging. 


\section{Principles of prompt physical availability of the military}

The DFP principles of the military are accuracy, progression and integration. These principles ensure that the military can accurately perform all the physical exercises, motor skills and abilities contained in the structure of a physical training program. They will progress physically and form their combat skills specific to each weapon/service and military specialty much faster. From a psychological point of view, the principles of DFP will develop the ability to work in a team, discipline, self-control, will support the automatic fulfillment of duties in difficult situations and will initiate an instinctive response to orders given by commanders.

Accuracy refers to the fact that precise movement depends on the structural and functional capabilities of the body, adequate mobility and suppleness, tolerance to bear extra weight, body composition and connection of the brain to muscles. All these motor patterns will allow the military to learn what the standard is and to perceive the difference between right and wrong techniques. The quality of the movement is as important as the high weight, the number of repetitions performed or the speed of execution and the formation of motor skills of the movements will develop through repeated executions and through the deliberate practice of physical activities.

Repetition, using mental images, can help refine precise movement patterns without exerting special physical effort. The principle of precision ensures the development of perception and awareness of body position in space ("the ability to feel, without visual participation, through deep sensitivity, movements passively imprinted on various body segments" ${ }^{\prime}$ ), to improve training parameters, evaluation results and performance in the field.

Progression refers to the proper dosage of physical effort, taking into account its fundamentals (volume, frequency, intensity and complexity) and the type of exercise needed to progressively stress the body, without causing the process called overtraining. Its purpose is to develop physical capacity to support the mastery of professional and combat-specific tasks. Pregnancy analysis includes the physiological requirements of the pregnancy and the potential performance problems or injury hazards that the military may face ${ }^{5}$. The correct progression of the basic parameters in the development of the effort and the variety of exercises used will evolve from the initial phase, to the improvement phase. The training performed in the initial phase of physical training will create a basic physical condition, which the military will use to progress safely to higher levels of operational physical capacity. Therefore, it is important to remember that the ability to move will require a consistent review of the basics before and after each progress to a higher level.

The principle of integration focuses on the activities and physical exercises performed by the military to enable them to fight and achieve victory. The army prepares the military and its units to fight and win, using a specific list of combat skills needed by all soldiers (regardless of rank, weapon or military specialty). These are a collection of individual motor skills related to the ability of a soldier to shoot with all categories of weapons, to walk in various terrains, to survive in extreme conditions and dangerous locations, to communicate with other soldier partners, to provide first aid in case of need, etc. The motor skills needed in a fight are those group skills designed to teach a unit to react and survive in various tactical combat situations. Being regularly supported by military physical education specialists (by training), all commanders must ensure (by testing) that their soldiers can perform all these skills.

Soldiers who follow these principles will become more physically prepared, as this is not a recreational fitness recipe. This physical training aims to develop physical capacity to support all military specialties and combat-specific tasks. Once the military achieves a high level of physical training in the initial phase, they must continue to build this basic training, along with the physical development of the military in accordance with the essential requirements of the mission to be fulfilled.

This doctrine (consisting of the three principles of DFP) integrates physical training with nonphysical training (areas that integrate with the fitness plan). The objectives of the training must take into account the ability of the military to perform physically and mentally demanding activities (in environments with extreme variations of heat, cold and humidity) at the same time as carrying 
heavy personal protective equipment. The recovery program between training sessions must be trained, measured and scheduled, and military physical education specialists must manage all obstacles that arise in the way of achieving the objectives (overtraining or stagnation of the level of performance). Consequently, military training sessions must take place at regular intervals, determined by the peak of the phase of adaptation of their body to the requests of the previous meeting ${ }^{6}$.

\section{Components of prompt physical availability of the military}

The set of military physical education exercises used to get in good physical shape is usually divided and measured into parts. They have often been labelled as components that have evolved with advances in exercise science and technology. The military must train in all components of fitness in order to meet an infinite range of operational challenges and physiological requirements.

Structural requirements are physical and cognitive characteristics that underlie increased work capacity. They allow the increase of work capacity through the systematic participation in physical training sessions, which create: a healthy body composition (the ratio between fat and muscle mass), an optimal ratio between weight and height, a high bone density (strong bones), a flexibility good statics (which will also help improve balance and coordination), a fast reaction time and an improved perception of body position and movement. In short, the military needs these structural requirements to begin training and complete as many duties as possible. "The success of the forces engaged in the conflicts depends to a large extent on the value of the motor performance and the level of mental qualities of the personnel serving the armament, equipment and fighting technique" 7 .

The physical training system must be designed so that the military can progress through training (regular and gradual in intensity and complexity) that will develop to the maximum their mental toughness ${ }^{8}$ and combat skills. Some may achieve higher individual levels of performance, inspiring others to want the same, but the maximum physiological functional capacity of the entire subunit (ease of performing physical tasks in daily life) is the aspect that must be met. It is primarily interested in a commander, not the outstanding performance of a single soldier.
When a soldier has to lift a weight of $50 \mathrm{~kg}$ and his maximum force is $150 \mathrm{~kg}$ (this refers to the largest load he can handle at a time ${ }^{9}$ ), this effort is relatively easy. His high level of muscle strength will allow him to use relatively less effort to complete the task, thus conserving his energy for the next effort. The same weight will be much heavier and the effort much more intense for someone whose maximum strength is $75 \mathrm{~kg}$. The closer the weight of the material to be handled to the maximum force of a soldier, the greater the risk of injury. The leaders of the activities must differ and individualize the physical training program of the military in order to improve the absolute workload and to avoid the occurrence of injuries. Those who will understand and apply the concept of maximum strength by quantifying the physical training sessions starting from its value, will strictly individualize the trainings in accordance with the requirements of the mission to be performed.

The prompt physical availability of the military must include in particular the following components: muscular strength, functional muscular hypertrophy, muscular endurance, aerobic endurance, anaerobic endurance and muscular power.

Muscular strength is the amount of force that a muscle or group of muscles can generate through the tension they exert during muscle contractions. Examples of exercises and situations when muscular force is mainly used: hanging on the fixed bar with the arms flexed and the chin above the bar (minimum time of 20 seconds), pushing from lying with the dumbbell, kneeling with the dumbbell at the nape of the neck, straightening with the dumbbell or extracting a wounded soldier through a tower hatch. However, the most useful way to measure muscle strength is the $1 \mathrm{RM}$ test (a maximum repetition) which determines the maximum weight that a soldier can handle.

The high levels of force that are reached during missions can certainly be achieved without maneuvering maximum weights endangering the bodily integrity of the military. In fact, specialists must take into account the results obtained by the military in the 1RM test and set tasks for subordinates, so that they use about $80-90 \%$ of their values. In this sense, the formula for calculating the value of a maximum repetition can also be used: 


\section{$1 R M=(0.033 x$ number of repetitions performed $x$ value of handled weight) \\ + Value of handled weight.}

Therefore, regular testing to determine the maximum value of muscle strength is important to monitor progress and to modify the physical training program according to individual needs. "The level of development of this quality, together with the resistance in particular, directly conditions their capacity for effort, an essential factor in the successful fulfillment of the entrusted missions and, at certain moments, in the very survival of the combatant or his comrades" 10 .

Functional muscle hypertrophy ("usable muscle pathway") is a complex process of increasing muscle size, which can be achieved through specific (hypertrophic) training in which sessions of developing muscle strength and muscular endurance are combined. The term functional refers to the fact that the military must train so that they can perform physical activities at the highest possible level, both in the military environment and in everyday life. To trigger muscle hypertrophy, the military should use moderate and heavy loads (between $65-85 \%$ of 1RM), a higher number of repetitions/training, short breaks between sets of exercises and a variety of speed of movement.

Muscular endurance is the ability of a muscle or muscle group to sustain an effort (to repeatedly perform contractions against a force) for a long period of time. It refers to the number of repetitions in a single exercise that a soldier can perform without having to stop for rest. The greater the muscular endurance, the greater the number of repetitions that the military can perform. Examples include: lifting and placing materials in a truck, loading a cannon with projectiles or performing calisthenics exercises at the fixed bar. In combination with aerobic and anaerobic endurance, muscular endurance is needed to withstand the transport of heavier and heavier loads, in varied terrain, over long distances and at higher speeds. The countertime buoyancy test ${ }^{11}$, part of the half-yearly assessments in military physical education, is a test often used to measure the muscular endurance of the upper train.

Aerobic endurance is the ability to activate large muscle groups for a longer period of time (over two minutes), depending on the functional state of the cardiovascular system (which provides oxygen and nutrients to the muscles). Although aerobic training is low intensity, a large volume without proper dosing (series, repetitions, weight, frequency) can cause overtraining. If the same rhythm is maintained, the large loads transported during aerobic activities tend to change the fitness component from aerobic to anaerobic. The military, regardless of their level of physical training, will begin to slow down when carrying heavy loads, which will significantly reduce the effect of aerobic training and increase the risk of injuries. Examples of aerobic efforts by the military: running in various terrain and fast long-distance travel, marches, patrols, etc.

Anaerobic endurance refers to the ability to sustain intense, short-term physical activity (about one minute). At this type of effort, the muscles with rapid contraction are the biggest contributors. The fuel for this type of intense exercise is derived mainly from energy sources that are already present in the body (such as the breakdown of glycogen into monosaccharide's, such as glucose). Anaerobic endurance is finite and is therefore associated with complete fatigue. The high level of anaerobic resistance is essential for the transport of heavy loads. Examples of anaerobic efforts made by the military: sprints, jumping over various obstacles, lifting weights, hand-to-hand combat with or without individual weapons, rapid movement carrying a heavy weight, etc. 'Increasing physical and mental demands, specific to the modern battlefield, make endurance a particularly important factor by which the military can overcome the early onset of fatigue, both intellectually, sensory, emotional and physical"12.

Muscular power is the ability to move a weight (including body weight) as fast as possible (applying force over time). Muscle strength is the result of both strength and speed requirements imposed by performing an activity, which can be described as the rate of work per unit time. The duration of training for the development of muscle strength is measured in seconds (or fractions of a second) and is characterized by maximum effort. Specific training will include explosive strength exercises (4 - 6 repetitions/series) performed with difficulty or resistance and followed by long rest intervals. If practiced consistently in training, they 
can improve the physical performance needed to carry out combat actions and reduce the risk of military injuries during activities involving explosive movements of force, speed and power with rapid acceleration. Examples of activities in which muscular power is used: throwing hand grenades at a distance, long jumps over obstacles, evacuating the wounded, pushing a vehicle stuck in the mud, etc.

\section{Conclusions}

Things that the military focuses on tend to have a positive effect on their career trajectory. When the military learns to pay more attention to their health and fitness, the condition of the body will be better and their level of physical training will be higher. They are able to create new neural pathways and, implicitly, new habits that will change their ways of reacting, deciding and behaving.

In military structures where the choice of a healthy lifestyle is appreciated and encouraged, its members have a greater capacity for self-control needed to make the right choices. When the military learns to focus on positive events, they are more likely to overcome negative moments, which we all tend to see first. In order to successfully physically prepare a subunit, the military physical education specialist must have the ability to give three times more positive/appreciative feedback than negative/ critical feedback.

The military has their own perspective on physical education, consisting of personal life history, lived emotional experiences and received education. Changing perspectives requires deliberate hard work, both on their part and on the part of commanders and specialists in the field of military physical education, to guide the training, teaching and mentoring of the physical training of the military. Focusing on DFP concepts, principles, and components can have a positive impact on the military's vision of the military organization.

I believe that the modern obsession with performing training sessions with a constantly high intensity and rapid development of excessive muscle mass in order to have a beautifully proportioned body is detrimental to health and normal life. There are many lessons learned from the experience of previous generations that we need to keep in mind, especially the true meaning of military physical education. The systematic performance of effective physical activities for several years, avoiding the risk of injuries caused by physical overload, in order to improve the motor skills necessary for fighters (however complex they may be), should be the ultimate goal in creating a physical availability to the military.

\section{NOTES:}

1 G.C. Ciapa, Physical training of the Romanian Army soldiers in modern conflicts, "Carol I" National Defence University Publishing House, Bucharest, 2018, p. 56.

2 https://www.romedic.ro/ritmul-cardiac-in-timpul-antr enamentelor-fizice-0C 34797, accessed on 05.05.2021.

$3 \mathrm{https}: / /$ www.andreirosu.org/2014/04/elucidarea-mister ului-alergarii-in-tempo, accessed on 06.05.2021.

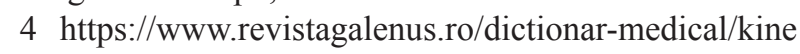
stezie, accessed on 20.04.2021.

5 https://muhaz.org/universitatea-din-bacu.html?page $=7$, accessed on 21.04.2021.

$6 \mathrm{https}: / /$ www.escalada.verticon.ro/antrenament/princi pii.htm, accessed on 24.04.2021.

7 A.D. Pelmuş, Development of the motor capacity of the military personnel, Publishing House of the TechnicalEditorial Center of the Army, Bucharest, 2021, p. 118.

8 It refers to any set of positive attributes that help a soldier cope with difficult situations.

9 "1RM" (one maximum repetition).

10 M.C. Istrate, "Strength - a driving quality with an essential impact in the military activity", Bulletin of "Carol I" National Defence University No. 3/2020, Bucharest, p. 210.

11 Female soldiers will perform floats with knee support (semi-floats).

12 A.D. Pelmuş, op.cit., p. 69.

\section{REFERENCES}

*** FM 7-22, Army Physical Readiness Training, Headquarters, Department Of the Army, Red Bike Publishing, 2013.

*** FM 7-22, Holistic health and fitness, Headquarters, Department Of the Army, Washington DC, 2020.

*** Military Physical Education Regulations, Army Technical-Editorial Center Publishing House, Bucharest, 2013.

Andrei I., The importance of physical training in the military training process, "Carol I" National Defence University Publishing House, Bucharest, 2015.

Băițan G.F., Physical training of the Romanian Army soldiers in the context of NATO integration, "Carol I" National Defence University Publishing House, Bucharest, 2019.

Ciapa G.C., Physical training of the Romanian Army soldiers in modern conflicts, "Carol I" 
National Defence University Publishing House, Bucharest, 2018.

Istrate M.C., "Strength - a driving quality with an essential impact in the military activity", Bulletin of "Carol I" National Defence University No. 3/2020, Bucharest.

Pelmuș A.D., Development of the motor capacity of the military personnel, Publishing House of the Technical-Editorial Center of the Army, Bucharest, 2021.

Pop N.H., Zamora E., Increasing muscle volume and strength - theoretical, practical and methodical elements, Risoprint Publishing House, Cluj-Napoca, 2007.

https://www.romedic.ro/ritmul-cardiac-intimpul-antrenamentelor-fizice-0C34797

https://www.andreirosu.org/2014/04/eluci darea-misterului-alergarii-in-tempo

https://www.revistagalenus.ro/dictionarmedical/kinestezie

https://muhaz.org/universitatea-din-bacu. $\mathrm{html}$ ?page $=7$

https://www.escalada.verticon.ro/antrenament/principii.htm 